\title{
O turismo rural pedagógico focado na educação ambiental como ferramenta complementadora do ensino fundamental
}

\author{
The pedagogical rural tourism focused on environmental education as a \\ complementary tool of elementary education
}

\author{
Thaisa Emanuelli Vianna (VIANNA, T. E.) ${ }^{*}$
}

\begin{abstract}
RESUMO - Este trabalho tem como objetivo central analisar as questões referentes ao turismo rural pedagógico e como ele pode ser um mecanismo eficaz na complementação do ensino da educação ambiental, isto fazendo uma inter-relação entre a teoria vista em sala de aula com a prática vivenciada em um local. Para tanto a pesquisa efetuada foi referenciada com autores relacionados aos temas do turismo rural, turismo pedagógico e educação ambiental, realizando ainda um estudo de campo na Propriedade Agrícola Framora, localizada em Rio Azul (Paraná, Brasil) para verificar quais as possibilidades de trabalhar tal segmento do turismo e como correlacionar a saída a campo com a aula em sala, tornando eficaz e mais abrangente o conhecimento do aluno, permitindo assim que o mesmo reflita sobre dados da sociedade.
\end{abstract}

Palavras-chave: Atividades pedagógicas; Cidadania; Educação ambiental; Turismo rural pedagógico.

ABSTRACT - This paper aimed to analyze issues related to teaching rural tourism and how it can be an effective mechanism to complement the teaching of environmental education, this by an interrelationship between theory seen in the classroom with the practice experienced in a place. For that the research was performed referenced with authors related to rural tourism issues, educational tourism and environmental education, still conducting a field study in Propriedade Agrícola Framora, located in Rio Azul (Paraná, Brazil) to verify what the possibilities of working such tourism segment and how to correlate the output field in the classroom, making effective and comprehensive understanding of the students, thus allowing these students reflect about that subject.

Key words: Pedagogical activities; Citizenship; Environmental Education; Pedagogical Rural Tourism.

\footnotetext{
* Formação: Graduação em Turismo (Bacharelado) pela Universidade Estadual do Centro Oeste (UNICENTRO) - Irati (PR). Especialização em andamento em Educação Especial com Ênfase em Libras pelo Instituto Superior de Aprendizagem Multidisciplinar (ISAM) - Irati (PR). Endereço físico para correspondência: Rua Cafieiro Corsi, 276. CEPA: 84560-000 - Rio Azul - Paraná (Brasil). Telefone para contato: 14 42-9141-3735/14 42-3463-1825. E-mail: temanuelli@yahoo.com.br
} 


\section{INTRODUÇÃO}

O desenvolvimento deste trabalho refere-se à importância de um estudo aprimorado em relação ao turismo rural pedagógico, visto constatar-se existir poucos pesquisadores na efetiva área, sendo necessária a união da atividade turística rural com a de cunho pedagógico para poder compreender a necessidade de um planejamento adequado e do benefício que tal segmento poderia proporcionar.

Importante salientar que a atividade em questão pode contribuir eficazmente para o ensino da educação ambiental, algo que não está orientado somente no meio ambiente em si, mas em um contexto de cidadania, ética e sociabilidade.

Desta forma, a metodologia utilizada foi a de estudo bibliográfico referente aos temas centrais do turismo rural, turismo pedagógico, a união de ambos desenvolvendo o turismo rural pedagógico e da educação ambiental, analisando a linha de pesquisa de como o meio rural poderia contribuir para a prática do ensino pedagógico in loco.

Como instrumento de objeto de pesquisa deste trabalho, será estudada a propriedade agrícola Framora (Rio Azul, Paraná, Brasil), sendo que para analisar o processo de produção desenvolvido e fazer uma relação com as questões de educação ambiental (assim como analisar a possibilidade da oferta do turismo rural pedagógico focado na educação ambiental), foram realizadas visitas in loco que possibilitaram a aplicação das técnicas de entrevista e observação.

Tratando-se das teorias aplicadas na propriedade Framora, referem-se aos conteúdos de Ciências e Geografia, alinhadas com base no Projeto Político Pedagógico da Escola Municipal Professora Vanda Hessel; e também das disciplinas de Língua Portuguesa e Artes, trabalhadas em sala de aula, mas com relações à educação ambiental.

Assim, a pesquisa aqui apresentada acerca do turismo rural pedagógico na propriedade agrícola Framora consiste em um estudo sobre a atividade turística realizada no meio rural e sua importância, bem como o desenvolvimento e relação do turismo pedagógico com o espaço rural, criando possibilidades de aprendizado para alunos primários e de como a educação ambiental poderia ser trabalhada de forma prática nas escolas. 


\section{PERSPECTIVAS DO TURISMO RURAL PEDAGÓGICO}

O Turismo Rural Pedagógico é uma atividade relativamente nova no Brasil e que deve ser analisada de forma abrangente, visto que possibilita ao educando aprimorar seus conhecimentos de forma dinâmica, além de unir o turismo com a educação e existir de fato a necessidade de deslocamento, tempo, manifestações culturais, meio ambiente, entre outros aspectos.

Primeiramente pode-se compreender por turismo a atividade realizada por determinado tempo em um local adverso ao rotineiro, em que as pessoas irão usufruir dos atrativos naturais, culturais, materiais e imateriais de forma consciente no seu tempo disponível para lazer.

Barbosa (2005) cita que o turismo é uma atividade transformadora do espaço em que as viagens realizadas beneficiam (se feitas de forma planejada e organizada) os locais receptores, possibilitando ao turista aproveitar os bens da natureza sem que precise consumi-los ou esgotá-los, englobando os setores de hotelaria, transporte, esporte, lazer, repouso, arte, cultura, exposições, entre outros.

Considerou-se ser necessário mencionar que a atividade turística quando desenvolvida no espaço rural, evidencia também a população, o estilo de vida dos proprietários e demais moradores, a cultura, entre outras coisas.

Segundo Paes-Luchiari, Bruhns e Serrano (2007), o turismo rural atrai os turistas por ser uma forma de descanso e recreação em que o turista pode observar o cultivo das culturas agrícolas, criação de animais, a natureza local, provar da gastronomia rural e demais atividades, fazendo com que o tempo de descanso seja aproveitado de maneira a contribuir para o turista de forma cultural; e mais, que a possibilidade de vivenciar pequenas sutilezas do clima campesino, da cultura agropastoril, da alimentação saudável ou até mesmo pitoresca são relevantes potenciais que atraem o turista das áreas urbanas.

Pode-se dizer que o desenvolvimento do turismo rural ocorre quando os proprietários percebem o potencial de suas propriedades e passam a conciliar as atividades agropastoris já desenvolvidas com o turismo.

Nas abordagens de Graziano da Silva, Vilarinho e Dale (1998) o turismo rural possui duas características relevantes: a primeira refere-se ao desenvolvimento de regiões que não dispõem de atrativos turísticos relevantes; a segunda diz respeito à 
criação de postos de trabalho com reduzido volume de investimento. Os autores ressaltam ainda que as atividades do turismo realizadas no meio rural geram ocupações complementares, ou seja, o turismo passa a ser secundário e realizado de forma agregada àquelas já existentes.

Outro ponto importante de mencionar, segundo Zanoni e Stefano (2004), é o fato de que existem crianças que nunca tiveram contato com o meio rural, cresceram no ambiente urbano sem o contato com animais e a cultura do campo.

Nesta contextualização, no meio rural se pode desenvolver o turismo de forma pedagógica para que os alunos relacionem a teoria vista em sala de aula com a realidade de um determinado local, de forma dinâmica, sendo que poderão aprender mais facilmente os conteúdos e relacioná-los com o dia a dia.

Além disso, a fase de desenvolvimento e crescimento das crianças permite um maior aprendizado sobre consciência e molde de atitudes relevantes, tanto para o meio ambiente, quanto para a sociedade, levando em consideração a questão da educação ambiental como fomentadora da clarificação de valores, segundo Carvalho (2001).

Assim sendo, para iniciar as abordagens sobre educação ambiental apresenta-se o conceito adotado na Conferência Intergovernamental de Tbilisi: (1977, apud BRASIL, 2013 [s./p.]) $)^{1}$ em que se discorre que:

A educação ambiental é um processo de reconhecimento de valores e clarificações de conceitos, objetivando o desenvolvimento de habilidades e modificando as atitudes em relação ao meio, para entender e apreciar as interrelações entre os seres humanos, suas culturas e seus meios biofísicos.

É a partir desta conferência que a preocupação com a sociedade e o ambiente passa a ter maior ênfase, ampliando a visão de forma global, ou seja, as condições voltadas para a conscientização dos valores do indivíduo e da natureza passam a ser de caráter mundial, abrangendo todos os países.

Sendo assim, é perceptível a questão de que a educação ambiental está baseada na sociedade como um todo. Segura (2001, p. 42) menciona que na educação ambiental se "passou a propagar uma nova proposta de vida e de compreensão do mundo que

1 Disponível em: <http://www.portaleducacao.com.br/biologia/artigos/27425/conferencia-de-tbilisi1977>. 
valoriza valores éticos, estéticos, democráticos e humanistas, partindo do princípio de respeito às diversidades natural e cultural".

Há, notoriamente, o fato de que a ênfase dada na questão da educação ambiental não pode ser alicerçada somente no meio ambiente em si, mas também na sociedade como um todo. Para Ruscheinsky (2007) a educação ambiental, aliada à questão de sustentabilidade não pode ser imposta como a ideia de intocabilidade do meio, mas sim como uma inclusão social e econômica, de forma a gerar o bem estar de todos, sendo possível utilizar o meio natural e os recursos nele disponíveis de forma consciente, agregando valor cultural, social e econômico para a comunidade inserida neste meio.

Nesta ideologia de que a educação ambiental não está aprisionada ao meio ambiente, Tristão (2004) contextualiza a formação de valores sustentáveis em um conjunto de ações sociais, políticas, econômicas e ambientais, acarretando a educação ambiental em sintonia com a social.

Importante salientar que para ocorrer a sintonia entre as questões ambiental e social torna-se necessária a participação do sistema de ensino na efetivação da educação ambiental, sendo necessário que os educadores auxiliem e motivem os alunos a buscar soluções para os problemas da sociedade (HIGUCHI; AZEVEDO, 2004).

Neste sentido, pode-se mencionar a questão da cidadania que, segundo Guimarães (1995), ocorre juntamente com a educação ambiental, uma vez que tal prática é capaz de transformar valores e atitudes, construindo a ética e a conscientização da relação integrada do ser humano, da sociedade e da natureza, objetivando, portanto, um equilíbrio em escala local e global.

Assim, o turismo pedagógico surge como uma oportunidade para que o aluno observe, reflita e registre dados sobre questões da atualidade, a fim de que no futuro se torne um adulto consciente, sendo que Bonfim (2010) complementa que ao reconhecer a necessidade do sistema educacional no desenvolvimento de práticas educativas, o turismo pedagógico insere-se como uma atividade construtiva do sujeito social.

Uma das principais características do turismo pedagógico, segundo Bonfim (2010), é que ele ocorre durante o ano letivo de escolas e não no período de férias, costumeiramente visto na atividade turística em geral e que esta é uma forma de desenvolver as crianças no âmbito social, crítico e educativo, pois o espaço turístico passa a ser transformado em educação fora da sala de aula. 
Nesta linha de pesquisa pode ser mencionada a educação pelo turismo, englobando o ensino prático por intermédio da atividade turística como uma atividade paralela às desenvolvidas em sala de aula, ou seja, o turismo como fonte contribuinte para a contextualização dos conteúdos programáticos, "conduzindo o jovem a pensar nas mudanças que ocorrem ao seu redor, oferecendo-lhe ferramentas para que consiga produzir conhecimento" (SILVA et al, 2013, p. 258).

Neste mesmo contexto Raykil e Raykil (2005) afirmam que a atividade turística de cunho pedagógico é um instrumento inovador utilizado em instituições de ensino (públicas ou privadas) que visa oferecer aos alunos a oportunidade de aprender os conteúdos abordados em sala de aula de forma dinâmica, tendo a possibilidade de trabalhar a interdisciplinaridade efetivamente falando.

Raykil e Raykil (2005) afirmam ainda que através da vivência dos alunos é possível desenvolver futuros turistas defensores dos patrimônios culturais e naturais, sendo que com viagens de cunho pedagógico é possível demonstrar a melhor forma de usufruir dos recursos disponíveis de forma consciente.

Sendo assim, e baseando-se também nas abordagens de Perinotto (2008), nota-se que a prática do turismo pedagógico ocorre principalmente em instituições de ensino que têm o intuito de tornar mais interessante o aprendizado dos alunos e com isso buscam parceria e apoio dos órgãos públicos.

Com base nas exposições teóricas apresentadas pode-se verificar que ao abordar a prática do turismo pedagógico há o potencial de inserir propriedades rurais na compreensão de educação ambiental, uma vez que a prática dos conteúdos abordados em sala de aula (conteúdos programáticos das disciplinas curriculares do ano letivo Ciências e Geografia) torna-se mais eficaz devido ao fato do aluno presenciar questões que, muitas vezes, não consegue assimilar somente em sala de aula.

Zanoni e Stefano (2004) citam inclusive que a atividade pedagógica realizada no meio rural é importante fator na questão da educação ambiental, uma vez que proporciona um contato maior com o meio natural de forma lúdica, ou seja, volta-se para a ideia inicial de que o turismo rural unido com o pedagógico é capaz de desenvolver e aprimorar a educação ambiental e cidadania dos alunos.

Para tanto a educação ambiental torna-se um eixo de ligação entre o meio ambiente e a sociedade, sendo necessário o planejamento adequado para que as questões 
de cidadania possam ser complementadas e abordadas na educação, seja educação básica ou educação superior, para que a conscientização acerca da temática seja mais bem desenvolvida.

Com as referências bibliográficas apresentadas, pôde-se verificar que a educação ambiental desenvolvida na atividade turística de cunho pedagógico, realizada em uma propriedade rural é uma maneira de proporcionar ao aluno o contato prático com questões cotidianas voltadas ao tema, bem como do princípio da cidadania, sendo que o aluno poderá relacionar a área rural com as questões que o professor/orientador poderá fazer menção.

Klein, Troian e Souza (2011) afirmam que o turismo rural pedagógico se caracteriza pelo conjunto de atividades que são desenvolvidas em uma propriedade rural, cujo objetivo é o de facilitar o aprendizado de alunos (independente da idade), desenvolvendo duplo favorecimento: dos proprietários através da valorização cultural e possível geração de renda complementar e dos estudantes com a possibilidade de aprendizado mais rico e diversificado, sendo que:

[...] o turismo rural pedagógico, enquanto prática educativa, pode ser entendido como uma estratégia que contribui não apenas para 0 conhecimento e valorização da agricultura e do espaço rural, mas também, para a promoção da educação ambiental, da educação nutricional e da segurança alimentar, favorecendo uma relação de proximidade e coerência entre homem e natureza, entre rural e urbano, entre conhecimento teórico (codificado) e conhecimento empírico (tácito) enfim, entre teoria e prática (KLEIN; TROIAN; SOUZA, 2011, p. 112-113).

Evidencia-se que é com o turismo rural pedagógico que as características rurais passam a ser entendidas não somente focando na produção primária dos alimentos, mas sim como um todo, valorizando o ambiente campesino em si, de forma a proporcionar aos alunos um aprendizado mais abrangente, visto a possibilidade de relacionar os conhecimentos com a realidade da sociedade.

Para Ficagna, Gazoni e Giuriatti, (2012) as pessoas que residem no meio rural possuem maior conhecimento prático em que é possível o estudante aprender questões diversas do meio campesino, sendo que há uma inter-relação de aprendizado: dos alunos com a forma prática de assimilar os conteúdos e também dos produtores que podem gerar retornos técnicos a partir da teoria adquirida com o auxílio dos visitantes. 
3 ESTUdO DE CASO: A PROPRIEDADE AGRÍCOLA FRAMORA DE RIO AZUL (PR) COMO FONTE ENRIQUECEDORA DA EDUCAÇÃO AMBIENTAL

O presente estudo refere-se à atividade turística rural de cunho pedagógico, frisando a educação ambiental como fonte de cidadania e desenvolvimento sócio/cultural/ambiental. Assim, consta o estudo de caso da Propriedade Agrícola Framora, localizada no município de Rio Azul (Paraná, Brasil) e consequentemente uma demonstração de como a atividade em menção poderia ser efetivada e desenvolvida de forma organizada a beneficiar produtores, professores e alunos.

Sobre os dados demográficos, pode-se mencionar que o município de Rio Azul está inserido na região Centro-Sul do Estado do Paraná (Figura 1), contando com cerca de 14 mil habitantes que estão distribuídos em uma área de 629,745 km (IBGE, 2014).

Rio Azul está localizado a 156,363 Km da capital do estado, Curitiba, e os municípios limítrofes são: Rebouças, Irati, Inácio Martins, Cruz Machado, Mallet e São Mateus do $\mathrm{Sul}^{2}$.

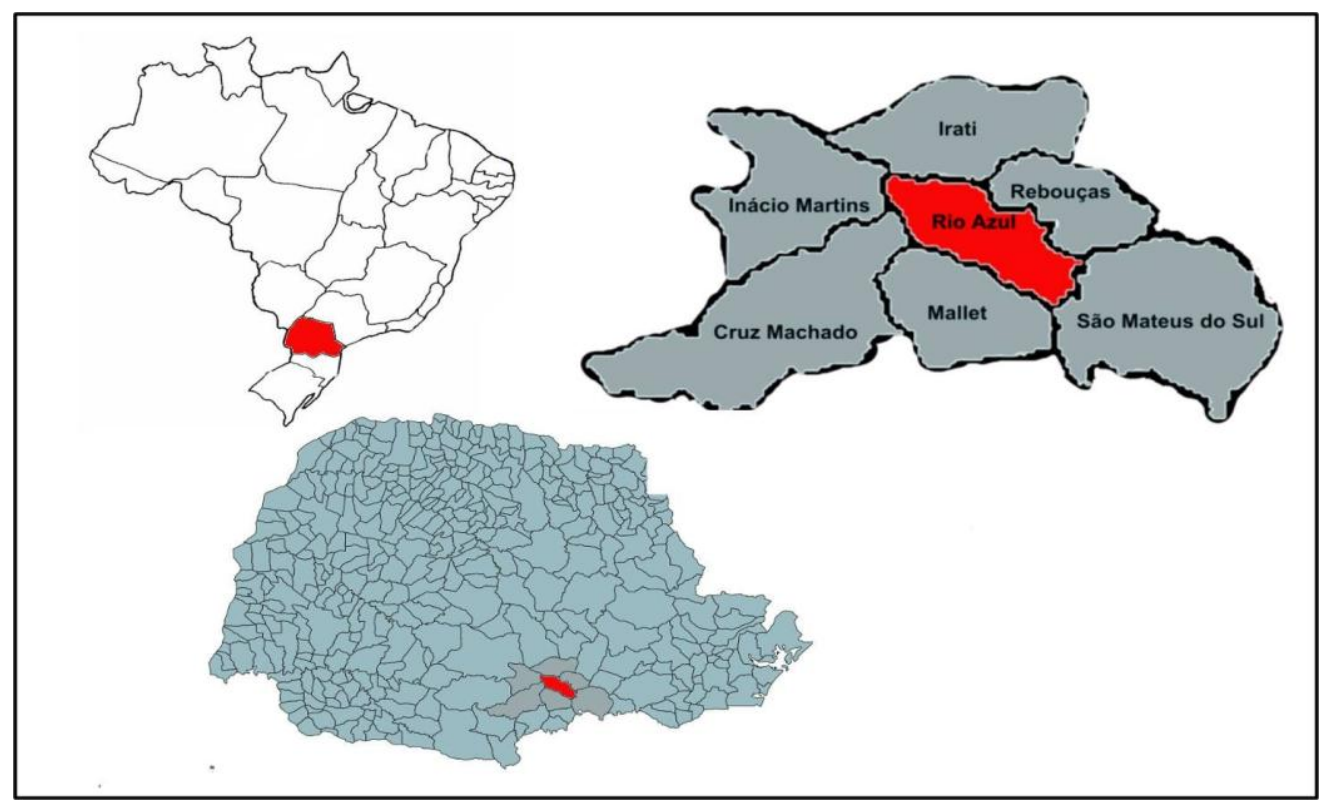

FIGURA 1 - LOCALIZAÇÃO DO MUNICÍPIO DE RIO AZUL (PR) NO CONTEXTO DO BRASIL E ESTADO DO PARANÁ.

ELABORAÇÃO: A autora, 2014.

\footnotetext{
${ }^{2}$ FONTE: Prefeitura Municipal de Rio Azul. Disponível em:

<http://www.rioazul.pr.gov.br/site/index.php/o-municipio/6-localizacao>.
} 
Abordando as questões econômicas do município, segundo Soares (2009), é por volta de 1920 que se iniciou o ciclo de cultivo de batata, fortemente difundido na região e também a cultura do fumo que ainda é a principal fonte de renda dos moradores do entorno do município.

Para Soares (2013) além destas atividades, as terras colonizadas em Rio Azul foram cenário também da produção de erva-mate e outras culturas, como a criação de bovinos, suínos, agricultura etc., ocorrendo uma miscigenação entre as culturas polonesas, ucranianas, italianas e caboclas que passaram a fazer parte da comunidade, fato que desencadeou a organização dos faxinais. ${ }^{3}$

Tratando-se da propriedade Framora, esta está localizada a $5 \mathrm{~km}$ da zona urbana do município de Rio Azul, na localidade de Pinhalzinho, sendo que tudo começou com a iniciativa do proprietário que não via rentabilidade, muito menos qualidade de vida no ramo tabagista, principal fonte de economia do município, e por tal motivo procurou diversificar a fonte de renda com outras formas de cultivo, segundo dados obtidos em entrevista com o proprietário Luis Sérgio Gurski ${ }^{4}$.

Constatou-se que na propriedade ocorria o cultivo e a produção de frutas vermelhas $100 \%$ orgânicas como morango, amora e framboesa, tendo a fabricação de geleias, compotas e licores; e, além disso, os proprietários compravam de fornecedores outras frutas (abacaxi, manga, pêssego, maracujá, goiaba, acerola e demais) que, devido ao fato de não serem da região, não eram $100 \%$ orgânicas como nas cultivadas na propriedade. Estas produzidas fora da propriedade tinham a finalidade de gerar a polpa para a fabricação de sucos.

Com a realização da entrevista, verificou-se ainda que o reconhecimento da agroindústria ocorreu com a divulgação da marca em feiras da região, congressos agropecuários e festas, propagando a ideia de produtos naturais e sua importância. Atualmente a agroindústria está firmada e cada vez mais os proprietários buscam melhorias, seja na expansão física, seja na expansão da venda dos produtos. Há que mencionar ainda que apesar da administração familiar e da produção em pequena

\footnotetext{
${ }^{3} \mathrm{O}$ sistema faxinal é aquele organizado de modo comunitário, encontrado em evidência na região CentroSul do Estado do Paraná. As principais características deste sistema são: uso comum da terra, produção agrícola basicamente de subsistência, a resolução de problemas acontece de forma comunitária, cultura e religiosidade fortemente preservadas, a cooperação entre os moradores é de relevância, entre outros aspectos (LEMES 2009).

${ }^{4}$ Entrevista realizada em 05 de agosto de 2013 pela autora para obtenção de dados.
} 
escala, a agroindústria continha todo o aparato de higienização e sanitização de acordo com a legislação.

Considerou-se relevante mencionar que os produtores da agroindústria já haviam participado de feiras realizadas pela ABAV (Associação Brasileira de Agências de Viagens) em 2005 e 2007, eventos turísticos em Cascavel, Maringá, Foz do Iguaçu, Ponta Grossa, entre outros, uma vez que sempre ocorriam convites para exposição em eventos em Minas Gerais e em Brasília.

Também se tornou relevante mencionar que a agroindústria é de cunho familiar, em que o atendimento e venda dos produtos eram feitos pelos próprios proprietários, sendo citada então a atividade da agricultura familiar, segundo dados obtidos em entrevista.

Sobre os recursos existentes verificou-se haver a presença de matas ciliares com reflorestamento de árvores nativas, sendo a água existente na propriedade considerada própria para consumo, isto segundo a certificação da EMATER (Instituto Paranaense de Assistência Técnica e Extensão Rural) cujos técnicos já realizaram pesquisas sobre a qualidade da água, consequência do correto reflorestamento e conservação do meio ambiente natural. Há que mencionar também que, além das árvores nativas da região, constatou-se a presença de algumas espécies diversas como o Pau-Brasil.

Percebeu-se ainda que poderia ser trabalhada a questão do mapa legal do meio ambiente da propriedade, que seria a configuração do espaço da propriedade e a correta forma de utilizar este meio, reflorestando e conservando o local, isto incluindo a retirada de animais nocivos à fonte de água existente na propriedade, que segundo o proprietário era algo precioso e fruto do esforço dos proprietários em utilizar o meio ambiente da forma correta.

Verificou-se também haver a possibilidade de ser abordada a separação correta do lixo, pois os proprietários realizavam tal atividade, conforme dados obtidos pela entrevista. Importante também foi o fato mencionado pelo proprietário de que não era feita a compostagem dos materiais orgânicos (isto porque a compostagem é um processo biológico de aceleramento da matéria orgânica que necessita de estrutura própria para isto e não se fazia importante pelo fato da produção não ter esta necessidade de aceleramento da matéria), mas estava havendo o reaproveitamento de sobras de alimentos que eram transformados em adubo orgânico para a produção. 
Considerou-se de relevo mencionar o fato da diversificação da produção, em que foi deixado de lado o cultivo do fumo (principal atividade econômica do município) para um cultivo orgânico sem a necessidade intensiva do uso de agrotóxicos. Na produção de frutas vermelhas poderia ser trabalhada também na questão da utilização correta do solo, pois segundo o proprietário, alternadamente ocorria a mudança das plantas de um local para o outro, para que o solo não perdesse suas propriedades e necessitasse se adaptar às novas plantas.

Considerou-se ainda o fato da existência de uma barreira de plantas altas no entorno das frutas vermelhas, que servia para proteger as plantas dos possíveis fungos, bactérias danosas e também restos de agrotóxicos oriundos das plantações de fumo existentes perto da propriedade Framora.

Outro ponto a ser mencionado é sobre a forma de processamento das frutas, em que a propriedade Framora era uma das mais importantes processadoras da região, fato este que atraía pesquisadores de diversas universidades para analisar como o processamento in natura poderia ser implantado em outros locais.

Relevante fazer menção da importância das frutas na alimentação, algo que foi mencionado pelo proprietário em suas palestras e visitas, sendo que isto estava sendo trabalhado com crianças de forma a estimular a alimentação saudável e relatar sua importância, numa tentativa de diminuir o consumo de alimentos industriais.

\section{ATIVIDADES PARA APRENDIZADO}

Abrangendo as disciplinas fundamentais de Ciências e Geografia para a educação ambiental, e nas pesquisas teóricas e de campo realizadas para este trabalho, apresenta-se a seguir as atividades possíveis de aprendizado na Agroindústria Framora de acordo com o conteúdo das disciplinas ministradas do primeiro ao quinto ano do Ensino Fundamental da rede pública de Rio Azul.

A partir da pesquisa teórica e de campo realizadas, foram elaborados cinco quadros (apresentados a seguir), em que se dispõem informações sobre os conteúdos que poderiam ser trabalhados pedagogicamente na agroindústria para as disciplinas mencionadas. 
Além destas, propõe-se também o trabalho com as disciplinas de Artes e Língua Portuguesa para o trabalho em sala de aula, a partir do que for visualizado pelo aluno durante a prática do turismo rural pedagógico como forma complementadora da educação ambiental.

QUADRO 1 - ATIVIDADES DE APRENDIZADO NA AGROINDÚSTRIA FRAMORA PARA O $1^{0}$ ANO

\begin{tabular}{|c|c|c|c|}
\hline DISCIPLINA & CONTEÚDOS & $\begin{array}{l}\text { ATIVIDADES NA } \\
\text { AGROINDSTRIA }\end{array}$ & $\begin{array}{l}\text { ATIVIDADES EM SALA } \\
\text { DE AULA }\end{array}$ \\
\hline Ciências & $\begin{array}{l}\text { No } 2^{0} \text { bimestre do ano } \\
\text { letivo os conteúdos } \\
\text { trabalhados em sala de } \\
\text { aula condizem com } \\
\text { estações do ano, } \\
\text { pomar e animais. } \\
\text { No } 3^{0} \text { são abordadas } \\
\text { questões de } \\
\text { alimentação saudável, } \\
\text { meio ambiente e } \\
\text { sentidos. }\end{array}$ & $\begin{array}{l}\text { Não utilização } \\
\text { agrotóxicos; } \\
\text { Produção } \\
\text { orgânicos; } \\
\text { Melhores estações para o } \\
\text { plantio; } \\
\text { Animais existentes no local; } \\
\begin{array}{l}\text { Diferenças no plantio das } \\
\text { frutas; }\end{array}\end{array}$ & \\
\hline Geografia & $\begin{array}{l}\text { No } 1^{0} \text { bimestre são } \\
\text { desenvolvidos } \\
\text { conteúdos referentes a } \\
\text { localização espacial e } \\
\text { espaço urbano x rural. }\end{array}$ & $\begin{array}{l}\text { Diferença do espaço rural e } \\
\text { urbano; } \\
\text { Importância do espaço rural } \\
\text { para a produção de } \\
\text { alimentos; } \\
\text { Maior número de árvores no } \\
\text { meio rural. }\end{array}$ & \\
\hline $\begin{array}{l}\text { Língua } \\
\text { Portuguesa }\end{array}$ & $\begin{array}{l}\text { Os } \\
\text { trabalhados referem-se } \\
\text { ao alfabeto, produção } \\
\text { textual, gêneros } \\
\text { textuais e oralidade. }\end{array}$ & & $\begin{array}{l}\text { Forme a palavra; } \\
\text { Contando a história; } \\
\text { Caça palavras. }\end{array}$ \\
\hline Artes & $\begin{array}{l}\text { O decorrer da } \\
\text { disciplina se dá com o } \\
\text { intuito de desenvolver } \\
\text { a coordenação motora } \\
\text { do aluno por meio de } \\
\text { atividades de recorte, } \\
\text { colagem, dobraduras, } \\
\text { entre outras coisas. }\end{array}$ & & $\begin{array}{l}\text { Fantoche; } \\
\text { Recorte e cole. }\end{array}$ \\
\hline
\end{tabular}

FONTE: A autora, 2014.

No primeiro quadro pode-se verificar a possibilidade de realizar atividades na agroindústria Framora relacionando as questões de sustentabilidade, práticas ecológicas, alimentação saudável e demais, sendo que para as disciplinas de Língua Portuguesa e Artes as atividades propostas deveriam dar ênfase para o que os alunos analisaram durante a prática no meio rural (do mesmo modo que todas as atividades propostas nos 
quadros seguintes para estas disciplinas devessem estar condizentes com o que foi visto na prática).

QUADRO 2 - ATIVIDADES DE APRENDIZADO NA AGROINDÚSTRIA FRAMORA PARA O $2^{0}$ ANO.

\begin{tabular}{|c|c|c|c|}
\hline DISCIPLINA & CONTEÚDOS & $\begin{array}{c}\text { ATIVIDADES NA } \\
\text { AGROINDUSTRIA } \\
\end{array}$ & $\begin{array}{c}\text { ATIVIDADES EM SALA } \\
\text { DE AULA }\end{array}$ \\
\hline Ciências & 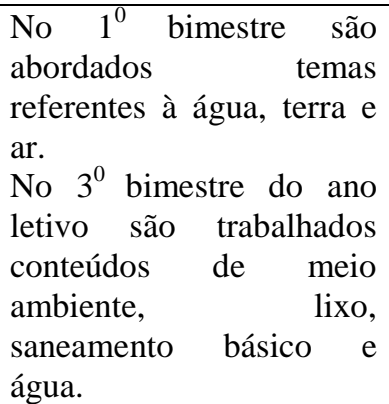 & $\begin{array}{l}\text { Processo de separação do lixo; } \\
\text { Compostagem e reutilização } \\
\text { de orgânicos; } \\
\text { Reflorestamento da mata } \\
\text { ciliar; } \\
\text { Malefícios dos agrotóxicos. }\end{array}$ & \\
\hline Geografia & $\begin{array}{l}\text { No } 2^{0} \text { bimestre as } \\
\text { abordagens } r \text { feitas } \\
\text { referem-se a paisagem } \\
\text { natural e modificada, bem } \\
\text { como de diferentes } \\
\text { paisagens existentes. }\end{array}$ & $\begin{array}{l}\text { Vales, morros, montanhas, } \\
\text { planícies, etc. } \\
\text { Mata ciliar, mata nativa, } \\
\text { espécies nativas e exóticas. }\end{array}$ & \\
\hline Língua Portuguesa & $\begin{array}{l}\text { Nas atividades são } \\
\text { desenvolvidos conteúdos } \\
\text { sobre textos, gênero } \\
\text { textual, pontuação e } \\
\text { acentuação, entre entre } \\
\text { outros assuntos. }\end{array}$ & & $\begin{array}{l}\text { Acentue; } \\
\text { Corrija o texto; } \\
\text { Reescrevendo a história }\end{array}$ \\
\hline Artes & $\begin{array}{l}\text { Na disciplina se procura } \\
\text { trabalhar a expressão dos } \\
\text { alunos utilizando métodos } \\
\text { de recorte, colagem, } \\
\text { sucatas, desenhos, entre } \\
\text { outras atividades. }\end{array}$ & & Vai e Vem \\
\hline
\end{tabular}

FONTE: A autora, 2014

As atividades práticas propostas no segundo quadro referem-se ao reflorestamento da mata ciliar e nativa, salientando que na propriedade Framora estava ocorrendo tal processo, além do fato de existir a possibilidade de trabalhar as questões referentes ao relevo e das espécies nativas de animais existentes no local, utilizando ainda o processo de compostagem para abordar a questão a separação e reutilização de materiais descartados no lixo. 
QUADRO 3 - ATIVIDADES DE APRENDIZADO NA AGROINDÚSTRIA FRAMORA PARA O $3^{0}$ ANO

\begin{tabular}{|c|c|c|c|}
\hline DISCIPLINA & CONTEÚDO & $\begin{array}{l}\text { ATIVIDADES NA } \\
\text { AGROINDUSTRIA }\end{array}$ & $\begin{array}{c}\text { ATIVIDADES EM SALA } \\
\text { DE AULA }\end{array}$ \\
\hline Ciências & $\begin{array}{l}\text { No } 3^{0} \text { bimestre as } \\
\text { abordagens referem- } \\
\text { se à reprodução das } \\
\text { plantas. } \\
\text { No } 4^{0} \text { bimestre são } \\
\text { trabalhados } \\
\text { conteúdos de ar, } \\
\text { poluição, seres } \\
\text { vivos } \\
\text { componentes. }\end{array}$ & $\begin{array}{l}\text { Problemas ocasionados pela } \\
\text { utilização de agrotóxicos; } \\
\text { Reprodução } \\
\text { desenvolvimento das plantas } \\
\text { (amora, morango } \\
\text { framboesa); } \\
\text { Poluição do ar e do rio; }\end{array}$ & \\
\hline Geografia & $\begin{array}{l}\text { No } 1^{0} \text { bimestre } \\
\text { trabalham-se } \\
\text { abordagens } \\
\text { referentes a relação } \\
\text { entre campo e } \\
\text { cidade, paisagem } \\
\text { natural e } \\
\text { modificada. }\end{array}$ & $\begin{array}{l}\text { Produtos da } \text { Framora } \\
\text { destinados para as escolas; } \\
\text { Diferença entre cidade e } \\
\text { meio rural; } \\
\text { Importância } \\
\text { reflorestamento. }\end{array}$ & \\
\hline $\begin{array}{l}\text { Língua } \\
\text { Portuguesa }\end{array}$ & $\begin{array}{l}\text { Neste caso são } \\
\text { abordadas questões } \\
\text { de gênero textual, } \\
\text { interpretação de } \\
\text { textos, verbos e } \\
\text { outras afins. }\end{array}$ & ----- & $\begin{array}{l}\text { Complete com o verbo; } \\
\text { Descreva; } \\
\text { Quadrinhos. }\end{array}$ \\
\hline Artes & $\begin{array}{lr}\text { A disciplina } & \text { tem } \\
\text { como } & \text { objetivo } \\
\text { desenvolver o } & \text { senso } \\
\text { artístico } & \mathrm{e} \\
\text { imaginário } & \text { dos } \\
\text { alunos como } & \text { fonte } \\
\text { auxiliadora } & \text { da } \\
\text { expressão corporal. }\end{array}$ & & $\begin{array}{l}\text { Jogo de boliche; } \\
\text { Instrumentos musicais. }\end{array}$ \\
\hline
\end{tabular}

FONTE: A autora, 2014.

O quadro 3 refere-se às atividades para o $3^{0}$ ano, dispondo da possibilidade de trabalhar a temática da relação entre a cidade e o ambiente rural, diferenças e necessidades, além do fato de existir na propriedade o reflorestamento e a produção de produtos orgânicos, fatos que poderiam ser abordados pelo professores para complementação da teoria trabalhada em sala de aula, como por exemplo do processo de reprodução das plantas e da importância do combate à poluição para que estas se desenvolvam adequadamente. 
QUADRO 4 - ATIVIDADES DE APRENDIZADO NA AGROINDÚSTRIA FRAMORA PARA O $4^{0}$ ANO

\begin{tabular}{|c|c|c|c|}
\hline DISCIPLINA & CONTEÚDOS & $\begin{array}{l}\text { ATIVIDADES NA } \\
\text { AGROINDUSTRIA }\end{array}$ & $\begin{array}{c}\text { ATIVIDADES EM SALA } \\
\text { DE AULA }\end{array}$ \\
\hline Ciências & $\begin{array}{l}\text { No } 1^{0} \text { bimestre são } \\
\text { trabalhadas questões de } \\
\text { alimentação. }\end{array}$ & $\begin{array}{l}\text { Produtos orgânicos } \\
\text { industrializados; } \\
\text { Importância da correta } \\
\text { alimentação; } \\
\text { Processamento de frutas; } \\
\text { Aproveitamento de alimentos. }\end{array}$ & \\
\hline Geografia & $\begin{array}{l}\text { No } 4^{0} \text { bimestre os } \\
\text { conteúdos } \\
\text { conpecíficos } \\
\text { condizem com o meio } \\
\text { ambiente do Município. }\end{array}$ & $\begin{array}{l}\text { Relevo de Rio Azul; } \\
\text { Espécies nativas (árvores e } \\
\text { frutas); } \\
\text { Rios, lagos e nascentes; }\end{array}$ & \\
\hline Língua Portuguesa & $\begin{array}{l}\text { Os conteúdos abordados } \\
\text { são de substantivos, } \\
\text { concordância verbal e } \\
\text { nominal, } \\
\text { numerais etc. }\end{array}$ & ---. & $\begin{array}{l}\text { Complete corretamente; } \\
\text { Jornal; } \\
\text { Cruzada. }\end{array}$ \\
\hline Artes & $\begin{array}{l}\text { A disciplina de artes visa } \\
\text { desenvolver a percepção } \\
\text { do aluno e a criatividade, } \\
\text { por intermédio de } \\
\text { atividades como artes } \\
\text { visuais em tela, desenhos } \\
\text { geométricos, música e } \\
\text { dança, entre outras. }\end{array}$ & & Cobra \\
\hline
\end{tabular}

FONTE: A autora, 2014.

Visto que a propriedade Framora era referência em produtos orgânicos e processamento de frutas, o quadro 4 destina-se a apresentar tais atividades ressaltando a importância da alimentação saudável e do aproveitamento de alimentos que seriam descartados. Além disso, os conteúdos programáticos referentes ao meio ambiente de Rio Azul poderiam ser desenvolvidos durante toda a visita ao local.

QUADRO 5 - ATIVIDADES DE APRENDIZADO NA AGROINDÚSTRIA FRAMORA PARA O $5^{0}$ ANO

\begin{tabular}{|l|l|l|c|}
\hline \multicolumn{1}{|c|}{ DISCIPLINA } & \multicolumn{1}{|c|}{ CONTEÚDOS } & \multicolumn{1}{|c|}{$\begin{array}{c}\text { ATIVIDADES NA } \\
\text { AGROINDUSTRIA }\end{array}$} & $\begin{array}{c}\text { ATIVIDADES EM SALA } \\
\text { DE AULA }\end{array}$ \\
\hline Ciências & $\begin{array}{l}\text { No } 4^{0} \text { bimestre são } \\
\text { abordados temas } \\
\text { referentes à } \\
\text { poluição e cuidados } \\
\text { para com a saúde. }\end{array}$ & $\begin{array}{l}\text { Utilização de agrotóxicos e } \\
\text { seus impactos (ar, água e } \\
\text { solo); }\end{array}$ & $\begin{array}{l}\text { Higienização local; } \\
\text { Poluição sonora; }\end{array}$ \\
\hline
\end{tabular}


Continuação.

\begin{tabular}{|c|c|c|c|}
\hline Geografia & $\begin{array}{l}\text { Os conteúdos sobre } \\
\text { Geografia } \\
\text { trabalhados com o } \\
5^{0} \text { ano referem-se ao } \\
\text { Estado do Paraná, } \\
\text { sendo que as } \\
\text { atividades } \\
\text { desenvolvidas na } \\
\text { Framora podem ser } \\
\text { de revisão dos } \\
\text { outros anos. }\end{array}$ & $\begin{array}{l}\text { Relevo, clima, vegetação, } \\
\text { etc.; } \\
\text { Poluição e reciclagem; } \\
\text { Produtos orgânicos e adubos } \\
\text { orgânicos. }\end{array}$ & \\
\hline $\begin{array}{l}\text { Língua } \\
\text { Portuguesa }\end{array}$ & $\begin{array}{l}\text { As atividades } \\
\text { desenvolvidas } \\
\text { referem-se } \\
\text { produção textual, } \\
\text { divisão silábica, } \\
\text { entre outras. }\end{array}$ & & $\begin{array}{l}\text { Separe corretamente; } \\
\text { Palavras trissílabas; } \\
\text { Produção de paródia. }\end{array}$ \\
\hline Artes & $\begin{array}{l}\text { O desenvolvimento } \\
\text { do senso crítico do } \\
\text { aluno ocorre por } \\
\text { meio de atividades } \\
\text { releitura de obras de } \\
\text { arte, cores e } \\
\text { classificações, } \\
\text { desenhos, artesanato } \\
\text { etc. }\end{array}$ & & Dinossauro. \\
\hline
\end{tabular}

FONTE: A autora, 2014

Salientando a questão da utilização de agrotóxicos, produtos orgânicos e poluição, no quadro 5 se abordam atividades a serem praticadas na propriedade Framora condizentes com tais fenômenos, utilizando os processos desenvolvidos para que a percepção dos conteúdos ocorra de forma eficaz, uma vez que os alunos podem criticar, questionar e até mesmo solucionar problemas ocorridos na sociedade.

Assim, ao analisar as possibilidades de aprendizagem na agroindústria Framora a partir do Projeto Político Pedagógico de uma escola da rede municipal, foi possível perceber que diversas atividades poderiam ser praticadas, utilizando o que os alunos visualizariam na prática de forma a complementar o ensino da educação ambiental. Evidencia-se que as disciplinas mencionadas têm a capacidade de aplicar a educação ambiental de acordo com os conteúdos abordados, o que necessitaria de um planejamento condizente para cada faixa etária.

Nos quadros acima, as propostas são as de adequar os conteúdos com a vivência, de forma a acarretar maior interesse pelos alunos em questionamentos, ou seja, 
abordando as práticas do local os alunos fariam a inter-relação dos trabalhos desenvolvidos em sala de aula.

Isto poderia ocorrer, por exemplo, com os estudos do que são agrotóxicos, seus malefícios e correta utilização, sendo que na Framora isto estaria sendo efetivado, de forma que o aluno estaria vendo na realidade o que é uma adubação orgânica e qual sua importância, podendo realizar questionamentos sobre o que de fato são agrotóxicos e adubação orgânica.

Desta forma, percebeu-se que a relação entre a teoria a ser vista em sala com a realidade local seria capaz de fortalecer e aprimorar o conhecimento dos alunos, algo importante para a efetivação da educação ambiental.

\section{CONSIDERAÇÕES FINAIS}

Nas abordagens referentes ao turismo rural, percebe-se que a atividade turística torna-se positiva se bem planejada, sendo que o contato com a cultura de um local e o ambiente natural é maior, pois as características rurais passam a ser entendidas de forma abrangente. Não menos importante está o fato de a atividade turística no meio rural aliada à educação, ser uma fonte de disponibilização de melhor ensino para os alunos, derivando assim o turismo rural pedagógico.

Tal segmento surge como alternativa de relacionar a teoria vista em sala de aula com a prática do dia a dia, acarretando um maior interesse de alunos que muitas vezes não têm oportunidade (e não são estimulados) de questionar problemas enfrentados na sociedade, sendo assim perceptível o fato de o aluno poder observar mais facilmente os conteúdos analisados em sala de aula, de forma a relacioná-los com a vivência.

Desenvolvendo uma análise teórica a respeito do turismo rural pedagógico é possível perceber que este segmento é relativamente novo no Brasil, pois as pesquisas realizadas até então são voltadas para o turismo rural e para o turismo pedagógico, ocorrendo que poucos autores analisam as questões da união destas duas atividades.

Salienta-se que independente da escassez de materiais verificou-se ser notório que o turismo rural pedagógico é importante devido ao fato que o aluno consegue analisar mais facilmente os conteúdos trabalhados em sala de aula das disciplinas curriculares, evidenciando a questão da educação ambiental. 
$\mathrm{Na}$ contextualização a respeito da educação ambiental, tal atividade pode ser analisada como fonte enriquecedora, conscientizadora e até mesmo transformadora dos valores dos seres humanos, algo que pode ser ainda complementado quando professores e pedagogos das instituições de ensino trabalham o tema com atividades pedagógicas focadas no ensino fundamental.

Evidencia-se que a proposta desta pesquisa teve como resultado a identificação da positividade da atividade turística rural de cunho pedagógico, ou seja, a partir da análise teórica dos temas centrais e da observação das possibilidades da Propriedade Agrícola Framora foram verificadas quais atividades poderiam ser trabalhadas de forma prática como complementação das teorias e conteúdos de Ciências e Geografia repassadas pelos professores em sala de aula, além do fato de mencionar como poderiam ser trabalhadas as disciplinas de Língua Portuguesa e Artes tendo relação com a educação ambiental e com o que os alunos presenciaram na propriedade.

Assim, pôde-se concluir que tal atividade é satisfatória e pode ser desenvolvida de forma eficaz, tendo em vista o município de Rio Azul (PR) e a propriedade Framora, para que os alunos tenham um aprendizado mais rico e dinamizador, encerrando-se aqui a pesquisa proposta.

Por fim, deve-se levar em consideração que a Agroindústria Framora possui potencial para maiores estudos em diversas áreas, como na educação alimentar, diversificação da produção, tecnologias de produção e processamento, história do município e do local, geografia e relevo, hospitalidade e receptividade dos proprietários como um diferencial, entre outros aspectos.

\section{REFERÊNCIAS}

BARBOSA, F. F. O turismo como um fator de desenvolvimento local e/ou regional. Caminhos da Geografia - revista on line, fevereiro de 2005. p. 107-114. Disponível em: $\quad<$ http://www.seer.ufu.br/index.php/caminhosdegeografia/article/view/15380>. Acesso em: 07/01/2014.

BONFIM, M. V. S. Por uma pedagogia diferenciada: Uma reflexão acerca do turismo pedagógico como prática educativa. Revista Turismo Visão e Ação - eletrônica, v. 12, n. 1, p. $114-129$, jan./abr. de 2010. Disponível em: <http://siaiweb06.univali.br/seer/index.php/rtva/article/view/1127/1511>.

Acesso em: 10/01/2014. 
BRASIL. Ministério do Meio Ambiente. Política de Educação Ambiental. 2013. Disponível em: <http://www.mma.gov.br/educacao-ambiental/politica-de-educacaoambiental>. Acesso em: 12/02/2014.

CARVALHO, I. C. M. Qual a educação ambiental? Elementos para um debate sobre a educação ambiental popular e extensão rural. Revista Agroecologia e Desenvolvimento rural Sustentável, Porto Alegre, v. 2, n. 2, junho de 2001. Disponível em: <http://www.isabelcarvalho.blog.br/pub/artigos/emater.pdf >. Acesso em: 07/01/2014.

FICAGNA, P. R.; GAZONI, M.; GIURIATTI, C. C. Agropecuária vinculada ao turismo rural "pedagógico" na agricultura familiar. SB Rural. Edição 85, ano 4 - 2012. Disponível em:

<http://www.ceo.udesc.br/arquivos/id_submenu/285/caderno_udesc_085.pdf>. Acesso em: 07/01/2014.

GRAZIANO DA SILVA, J.; VILARINHO, C.; DALE, P. J. Turismo em áreas rurais: suas possibilidades e limitações no Brasil. Caderno CRH, n. 28, p. 113-155, jan/jun. 1998. Disponível em:

<http://www.cadernocrh.ufba.br/viewarticle.php?id=214\&layout=abstract $>$. Acesso em: $13 / 01 / 2014$.

GUIMARÃES, M. A dimensão ambiental na educação. Campinas, SP: Papirus, 1995. Coleção Magistério: Formação e Trabalho Pedagógico.

HIGUCHI, M. I. G.; AZEVEDO, G. C. Educação como processo na construção da cidadania ambiental. Revista Brasileira de Educação Ambiental, Brasília, n. 0 - Rede Brasileira de Educação Ambiental, 2004. Disponível em:

<http://d3nehc6yl9qzo4.cloudfront.net/downloads/revbea_n_zero.pdf\#page=79>. Acesso em: 12/01/2014.

IBGE. Instituto Brasileiro de Geografia e Estatística. Rio Azul: dados gerais do município. Disponível em:

<http://cidades.ibge.gov.br/painel/painel.php?codmun=412200>.

Acesso em: 12/03/2014.

KLEIN, A. L.; TROIAN, A.; SOUZA, M. de. O Turismo Rural Pedagógico e a Educação Ambiental: As Ações Pedagógicas Desenvolvidas na Fazenda Quinta da Estância Grande - Viamão (RS). Revista eletrônica do mestrado em Educação Ambiental, 2011. Disponível em:

<http://www.seer.furg.br/remea/article/view/3197/1859>. Acesso em: 15/02/2014.

LEMES, P. H. S. Turismo comunitário e populações tradicionais: o caso do faxinal Barra Bonita no município de Prudentópolis - PR. Ponta Grossa, 2009. Disponível em: $<$ http://bicen-tede.uepg.br/tde_busca/arquivo.php?codArquivo=495>. Acesso em: 12/01/2014. 
PAES-LUCHIARI, M. T.; BRUHNS, H. T.; SERRANO, C. Patrimônio, Natureza e Cultura. Campinas, SP. Papirus, 2007.

PERINOTTO, A. R. C. Turismo pedagógico: uma ferramenta para a educação ambiental. Caderno Virtual de Turismo, v. 8, n. 1, 2008, p. 100-103. Universidade Estadual do Rio de Janeiro - Rio de Janeiro, Brasil. Disponível em: <http://www.spell.org.br/documentos/download/1908\%3E $>$. Acesso em: 10/01/2014.

RAYKIL, E. B; RAYKIL, C. Turismo pedagógico: uma interface diferencial no processo ensino-aprendizagem. In: Global Tourism, São Paulo, v. 1, n. 2, 2005.

RUSCHEINSKY, A. Educação Ambiental: abordagens múltiplas. Porto Alegre: Artmed, 2007.

SEGURA, D. de S. B. Educação ambiental na escola pública: da curiosidade ingênua à consciência crítica. São Paulo: Annablume: Fapesp, 2001.

SILVA, M. A. da; HOLANDA, L. A. de; SILVA, M. H. C. da; LEAL, S. R. Potencialidades e limites da relação entre turismo e educação: um estudo no Ensino Fundamental II em escolas públicas municipais de Recife e Olinda (Pernambuco, Brasil). Turismo e Sociedade, Curitiba, v. 6, n. 2, p. 253-275, abril de 2013. Disponível em: <http://ojs.c3sl.ufpr.br/ojs2/index.php/turismo/article/view/31926/20349>. Acesso em: $15 / 01 / 2014$.

SOARES, J. J. Inventário da oferta turística municipal - Rio Azul, 2009.

SOARES, J. G. Comunidades faxinalenses no município de Rio Azul-PR: gênese, características e transformações nos padrões espaciais de povoamento. Ponta Grossa, 2013. Disponível em:

$<$ http://bicen-tede.uepg.br/tde_busca/arquivo.php?codArquivo=767>. Acesso em: 12/01/2014.

TRISTÃO, M. Saberes e fazeres da educação ambiental no cotidiano escolar. In: Revista Brasileira de Educação Ambiental, Brasília, n. 0 - Rede Brasileira de Educação Ambiental, 2004. Disponível em:

<http://d3nehc6yl9qzo4.cloudfront.net/downloads/revbea_n_zero.pdf\#page=79>. Acesso em: 17/02/2014.

ZANONI, J.; STEFANO, S. R. Desenvolvendo o turismo rural em um meio de hospedagem rural. In: VII SEMEAD - SEMINÁRIOS EM ADMINISTRAÇÃO FEAUSP. 2004. Disponível em:

<http://www.ead.fea.usp.br/Semead/7semead/paginas/artigos\%20recebidos/Socioambie ntal/SA10_Desenvolvendo_turismo_rural.PDF>. Acesso em: 10/02/2014.

Recebido em: 30-04-2014.

Aprovado em: 30-05-2014. 